\title{
Differential association between obesity and coronary artery disease according to the presence of diabetes in a Korean population
}

Ki-Bum Won ${ }^{1,2}$, Hyuk-Jae Chang ${ }^{1,5^{*}}$, Hiroyuki Niinuma ${ }^{2}$, Jimin Sung ${ }^{3}$, In-Jeong Cho ${ }^{1}$, Chi-Young Shim , Geu-Ru Hong ${ }^{1}$, Young Jin Kim ${ }^{4}$, Byung-Wook Choi ${ }^{4}$ and Namsik Chung ${ }^{1}$

\begin{abstract}
Background: Coronary artery disease (CAD) is a major cardiovascular complication in diabetic patients. Despite the significant association between obesity and diabetes, the majority of the diabetic subjects are not obese in an Asian population. This study evaluated the association between obesity and coronary artery disease (CAD) according to the diabetes status in a Korean population.

Methods: The association between obesity and CAD using the parameters of any plaque, obstructive plaque, and coronary artery calcium score (CACS) $>100$ according to the presence of diabetes was evaluated in 7,234 Korean adults who underwent multi-detector computed tomography for general health evaluations. Obesity was defined as a body mass index $(\mathrm{BMI}) \geq 25 \mathrm{~kg} / \mathrm{m}^{2}$.

Results: The prevalence of obesity was significantly higher in diabetic subjects than in non-diabetic subjects, but the majority of the diabetic subjects were non-obese ( $48 \%$ vs. $37 \%, p<0.001$ ). The incidence of any plaque (58\% vs. $29 \%$ ), obstructive plaque ( $20 \%$ vs. $6 \%$ ), and CACS $>100(20 \%$ vs. $6 \%)$ were significantly higher in diabetic patients than in non-diabetic subjects ( $p<0.001$, respectively). Incidence of any plaque (33\% vs. $26 \%, p<0.001$ ), obstructive plaque ( $7 \%$ vs. $6 \%, p=0.014)$, and CACS $>100$ ( $8 \%$ vs. $6 \%, p=0.002)$ was significantly higher in non-diabetic subjects with obesity than in those without obesity, but the incidence of all coronary parameters was not different in diabetic subjects according to the obesity status. After adjusting for confounding risk factors including age, gender, hypertension, dyslipidemia, current smoking, and mild renal dysfunction, obesity was independently associated with increased risks of any plaque (OR 1.14) and CACS $>100$ (OR 1.31) only in non-diabetic subjects ( $p<0.05$, respectively). Multiple logistic regression models revealed that diabetes was independently associated with all coronary parameters.

Conclusion: Despite a significantly higher prevalence of obesity in diabetic subjects than in non-diabetic subjects, obesity is associated with the presence of any plaque and severe coronary calcification only in subjects without established diabetes among Korean population.
\end{abstract}

Keywords: Obesity, Diabetes, Coronary artery disease, Cardiac computed tomographic angiography

\footnotetext{
* Correspondence: hjchang@yuhs.ac

${ }^{1}$ Division of Cardiology, Yonsei Cardiovascular Center, Yonsei University

College of Medicine, 50 Yonsei-ro, Seodaemun-gu, Seoul 120-752, Republic

of Korea

${ }^{5}$ Severance Biomedical Science Institute, Seoul, Republic of Korea

Full list of author information is available at the end of the article
} 


\section{Background}

Diabetes is significantly associated with an increased risk of coronary artery disease (CAD). Although the pathogenesis of diabetes is complicated by multiple metabolism-related problems, a deterioration of insulin secretion and an aggravation of insulin resistance are 2 central defects in the pathogenesis of diabetes [1,2]. It is obvious that obesity is one of the major factors for insulin resistance. However, the criterion of obesity is dependent on ethnicity, and the prevalence of obesity differs according to ethnicity. In addition, despite the substantial increases in the prevalence of obesity and diabetes in Asia, the clinical features of the development of diabetes in Asia are explicitly different from those in other parts of the world, with diabetes developing in a much shorter time, at a younger age, and in subjects with much lower body mass index (BMI) in Asia [3]. The majority of individuals with diabetes are not obese, even with obesity defined as a BMI of more than $25 \mathrm{~kg} / \mathrm{m}^{2}$, and significant weight loss is observed during the course of the development of diabetes in Korean population [4]. Furthermore, several studies on the pathogenesis of type 2 diabetes reported that impaired insulin secretion is more prominent than insulin resistance, even in the status of impaired glucose tolerance $[5,6]$. Accordingly, whether obesity is an independent predictor for CAD in Asian diabetic subjects may be an important issue, but data are scarce in Asian populations.

The coronary artery calcium (CAC) score (CACS), which has developed to quantify the extent of CAC [7], is a good marker of coronary atherosclerosis $[8,9]$. CACS is closely correlated with the volume of coronary plaque measured by autopsy and is considered a surrogate marker for the overall coronary plaque burden [10-12]. A few previous studies investigated the relationship between obesity and CAC, but the results were inconsistent. Some reported a positive and independent association [13-15], while others reported a null [16-18], or even an inverse association [19]. Furthermore, most relevant studies were conducted in a Western population, in which obesity and CAD are more prevalent compared with other populations such as East Asian. In addition, they evaluated the association between obesity and CAC without considering the status of diabetes. Recently, coronary computed tomographic angiography (CCTA) was introduced as a novel noninvasive imaging approach for evaluating coronary atherosclerosis $[20,21]$, and it has high diagnostic accuracy in detecting CAD $[22,23]$. Therefore, we investigated the association between obesity and coronary atherosclerosis according to diabetes status using the noninvasive CCTA in Korean subjects with near-normal kidney function.

\section{Methods}

\section{Subjects}

This cross-sectional study consisted of 8,648 consecutive subjects who had undergone CCTA evaluation with 64-slice multi-detector computed tomography (MDCT) from January 2004 to April 2009 at Severance Cardiovascular Hospital. All subjects were referred for general health evaluations with following various indications: symptoms such as chest discomfort, dyspnea, or fatigue; no symptoms but having abnormal electrocardiographic test, previous history of peripheral artery disease or cerebrovascular disease, or the presence of multiple cardiovascular risk factors. Subjects were excluded for any one of the following criteria: (a) age $<30$ years $(n=69)$; (b) established chronic kidney disease or glomerular filtration rate (GFR) $<60 \mathrm{ml} / \mathrm{min} / 1.73 \mathrm{~m}^{2}$, estimated by the modification of diet in renal disease formula $(n=959)$; and (c) insufficient medical records $(\mathrm{n}=386)$. As a result, 7,234 subjects were included in this study. The study protocol was approved by the local ethics committee of our institution.

\section{Protocol of MDCT}

Data acquisition and image post-processing were performed in accordance with the Society of Cardiovascular Computed Tomography guidelines on CCTA acquisition $[24,25]$. Briefly, subjects with an initial heart rate $\geq 65$ beats/min before MDCT received a single oral dose of $50 \mathrm{mg}$ of metoprolol (Betaloc; Yuhan, Seoul, Korea) $1-2 \mathrm{~h}$ before $\mathrm{CT}$ examination unless $\beta$-adrenergic blocking agents were contraindicated (overt heart failure, atrioventricular conduction abnormalities, or bronchial asthma). Subjects were scanned with a 64-slice CT scanner (Sensation 64; Siemens Medical Solutions, Forchheim, Germany). Initially, a non-enhanced prospective electrocardiogram (ECG)-gated scan to evaluate CACS was performed with the following parameters: rotation time of $330 \mathrm{~ms}$, slice collimation of $0.6 \mathrm{~mm}$, slice width of $3.0 \mathrm{~mm}$, tube voltage of $100-120 \mathrm{kV}$, tube current of $50 \mathrm{~mA}$, and table feed/scan of $18 \mathrm{~mm}$. CCTA was then performed using retrospective ECG-gating with the following scan parameters: rotation time of $330 \mathrm{~ms}$, slice collimation of $64 \times 0.6 \mathrm{~mm}$, tube voltage of 100 $120 \mathrm{kV}$, tube current of $400-800 \mathrm{~mA}$ depending on patient size, table feed/scan of $3.8 \mathrm{~mm}$, and pitch factor of 0.2. ECG-based tube current modulation was applied to $65 \%$ of the $\mathrm{R}-\mathrm{R}$ interval. A real-time bolus-tracking technique was applied to trigger scan initiation. The total estimated average radiation dose for the multi-slice CT protocol was $8.7 \pm 1.5 \mathrm{mSv}$. Contrast enhancement was achieved using $60 \mathrm{~mL}$ of iopamidol (370 mg iodine $/ \mathrm{mL}$, Iopamiro; Bracco, Milan, Italy) injected at $5 \mathrm{~mL} / \mathrm{s}$, followed by an injection of $30 \mathrm{~mL}$ of diluted contrast (the ratio of saline to contrast agent was 7:3) and then 
$30 \mathrm{~mL}$ of saline at $5 \mathrm{~mL} / \mathrm{s}$ with a power injector (Envision CT; Medrad, Indianola, PA) via an antecubital vein.

Image reconstruction was carried out on the scanner workstation using commercially available software (Wizard; Siemens Medical Solutions, Forchheim, Germany). Axial images were reconstructed retrospectively at $65 \%$ of the RR interval for each cardiac cycle. If artifacts were present, then additional data sets were obtained for various points of the cardiac cycle, and the data set with the smallest artifact was selected for further analysis. The reconstructed image data sets were transferred to an offline workstation (Aquarius Workstation; TeraRecon, Inc., San Mateo, CA). Each lesion identified was examined using maximum-intensity projection and multiplanar reconstruction techniques on a short axis and along multiple longitudinal axes. Lesions were classified by the maximal stenosis of the luminal diameter observed on any plane.

\section{Measurement of $\mathrm{CT}$ variables}

CCTA data were evaluated by 2 experienced cardiac radiologists (Y.J.K. and B.W.C., who have 6 and 9 years of experience in cardiac $\mathrm{CT}$, respectively). This study primarily evaluated the presence of any plaque, obstructive plaque, and CACS $>100$. Both any plaque and obstructive plaque were divided into 2 subtypes according to the presence of coronary calcification following calcified or mixed plaque and non-calcified plaque, respectively. CACS was measured using a previously described method [7]. Because the frequency of CACS $>100$ in the Asian population is known to be lower than that in Caucasians, AfricanAmericans, and Hispanics [26], we used CACS $>100$ as the parameter for identifying severe coronary calcification.

Plaque was defined as structures $>1 \mathrm{~mm}^{2}$ within and/or adjacent to the vessel lumen that were clearly distinguished from the lumen and surrounding pericardial tissue. Obstructive plaque was defined as plaque with $\geq 50 \%$ luminal diameter stenosis. Calcified plaque was defined as plaque occupied by calcified tissue for $\geq 50 \%$ of the plaque area (density $>130$ Hounsfield units in native scans). Mixed calcified plaque was defined as plaque in which $<50 \%$ of the area is occupied by calcified tissue. Plaque without any calcium was defined as non-calcified plaque. CAD was defined as the presence of any coronary plaque and calcium identified by CCTA.

\section{Measurement of clinical variables}

Medical histories of hypertension, dyslipidemia, diabetes, and smoking status were systematically acquired for the subjects. Height, weight, and blood pressure were measured during visits. All blood samples, including those for triglycerides, high-density lipoprotein (HDL) cholesterol, low-density lipoprotein (LDL) cholesterol, and glucose, were obtained after a 12-h fast on the day of the CT scan as part of the clinical work-up. BMI was calculated as weight $(\mathrm{kg}) \div$ height $\left(\mathrm{m}^{2}\right)$, and obesity was defined as a BMI $\geq 25 \mathrm{~kg} / \mathrm{m}^{2}$. Hypertension was defined as systolic blood pressure $\geq 140 \mathrm{mmHg}$ and/or diastolic blood pressure $\geq 90 \mathrm{mmHg}$ or the use of antihypertensive treatment. Dyslipidemia was defined as total cholesterol $\geq 240 \mathrm{mg} / \mathrm{dL}$, $\mathrm{LDL} \geq 130 \mathrm{mg} / \mathrm{dL}, \mathrm{HDL} \leq 40 \mathrm{mg} / \mathrm{dL}, \mathrm{TG} \geq 150 \mathrm{mg} / \mathrm{dL}$, or treatment with lipid-lowering agents. Current smoking history was considered present if subjects consistently smoked or smoked within 1 month before the study. Mild renal dysfunction was defined as a GFR of $60-89 \mathrm{ml} / \mathrm{min} /$ $1.73 \mathrm{~m}^{2}$. Diabetes was defined as fasting glucose $\geq 126 \mathrm{mg} /$ $\mathrm{dL}$, the receipt of antidiabetic treatment, or a referral diagnosis of diabetes.

\section{Statistical analysis}

Continuous variables are expressed as the mean \pm SD or medians and interquartile range according to the distribution. Categorical variables are presented as n (\%). Continuous variables were compared using an independent t-test or Mann-Whitney's U-test, and categorical variables were compared using the $\chi^{2}$ test or Fisher's exact test, as appropriate. Univariate and multivariate logistic regression analysis for evaluating the impact of obesity and BMI on the presence of any plaque, obstructive plaque, and CACS $<100$ were performed separately for subjects with and without diabetes. Multivariate logistic regression analysis was adjusted for confounding risk factors including age, gender, hypertension, dyslipidemia, current smoking, and mild renal dysfunction. And, multivariate logistic models were analyzed to identify the impact of diabetes on the presence of any plaque, obstructive plaque, and CACS $<100$. The covariate-adjusted odds ratio (OR) and 95\% confidence intervals (CI) for each parameter were calculated. SPSS version 18 (SPSS Inc., Chicago, IL) was used for all statistical analyses, and $\mathrm{p}<0.05$ was considered significant.

\section{Results}

The clinical characteristics of the 7,234 subjects (52 \pm 10 years; $57 \%$ men) are listed in Table 1 . There were 6,345 non-diabetic (88\%) and 889 diabetic subjects (12\%). The overall prevalence of obesity in the present study was $38 \%$. The prevalence of obesity was significantly higher in diabetic subjects than in non-diabetic subjects (48\% vs. $37 \%$, $\mathrm{p}<0.001)$, but the majority of diabetic subjects were nonobese (Figure 1). The prevalence of hypertension, and dyslipidemia were significantly higher in diabetic subjects than in non-diabetic subjects ( $\mathrm{p}<0.001$, respectively). The incidence of any plaque (58\% vs. $29 \%$ ), obstructive plaque (20\% vs. $6 \%$ ), and CACS $>100$ (20\% vs. $6 \%$ ) were significantly higher in diabetic patients than in non-diabetic subjects ( $p<0.001$, respectively) (Figure 2). 
Table 1 Baseline characteristics

\begin{tabular}{|c|c|c|c|}
\hline & Non-diabetes $(n=6,345)$ & Diabetes $(n=889)$ & $\mathbf{P}$ \\
\hline Age (years) & $52 \pm 10$ & $58 \pm 9$ & $<0.001$ \\
\hline Men, n (\%) & $3569(56)$ & $565(64)$ & $<0.001$ \\
\hline BMI $\left(\mathrm{kg} / \mathrm{m}^{2}\right)$ & $24.1 \pm 2.9$ & $25.1 \pm 3.1$ & $<0.001$ \\
\hline $\mathrm{BMI}<18.5$ & $99(2)$ & $10(1)$ & \\
\hline BMI $18.5-24.9$ & $3920(61)$ & $455(51)$ & \\
\hline BMI $25.0-29.9$ & $2137(34)$ & $373(42)$ & \\
\hline $\mathrm{BMI} \geq 30.0$ & $189(3)$ & $51(6)$ & \\
\hline Obesity, n (\%) & $2326(37)$ & $424(48)$ & $<0.001$ \\
\hline Hypertension, n (\%) & $1716(27)$ & $427(49)$ & $<0.001$ \\
\hline Current smoking, n (\%) & $1351(22)$ & $186(21)$ & 0.801 \\
\hline Dyslipidemia, n (\%) & $3253(52)$ & $560(64)$ & $<0.001$ \\
\hline Total cholesterol (mg/dL) & $187(164,210)$ & $177(155,203)$ & $<0.001$ \\
\hline Triglyceride (mg/dL) & $121(87,170)$ & $135(97,187)$ & $<0.001$ \\
\hline HDL cholesterol (mg/dL) & $50(43,58)$ & $48(41,54)$ & $<0.001$ \\
\hline LDL cholesterol (mg/dL) & $119(97,141)$ & $111(89,137)$ & 0.007 \\
\hline Creatinine $(\mathrm{mg} / \mathrm{dL})$ & $0.90(0.80,1.00)$ & $0.90(0.80,1.00)$ & $<0.001$ \\
\hline GFR $\left(\mathrm{ml} / \mathrm{min} / 1.73 \mathrm{~m}^{2}\right)$ & $80(72,91)$ & $80(72,90)$ & $<0.001$ \\
\hline FBS $(\mathrm{mg} / \mathrm{dL})$ & $94(88,101)$ & $127(107,149)$ & $<0.001$ \\
\hline Any plaque, n (\%) & $1814(29)$ & $511(58)$ & $<0.001$ \\
\hline Obstructive plaque, n(\%) & $401(6)$ & $174(20)$ & $<0.001$ \\
\hline CACS > 100, n (\%) & $403(6)$ & $176(20)$ & $<0.001$ \\
\hline
\end{tabular}

Data are expressed as $\mathrm{n}(\%)$ or mean \pm SD. BMI, body mass index; CACS, coronary artery calcium score; FBS, fasting blood sugar; GFR, glomerular filtration rate; HDL, high-density lipoprotein; LDL, low-density lipoprotein.

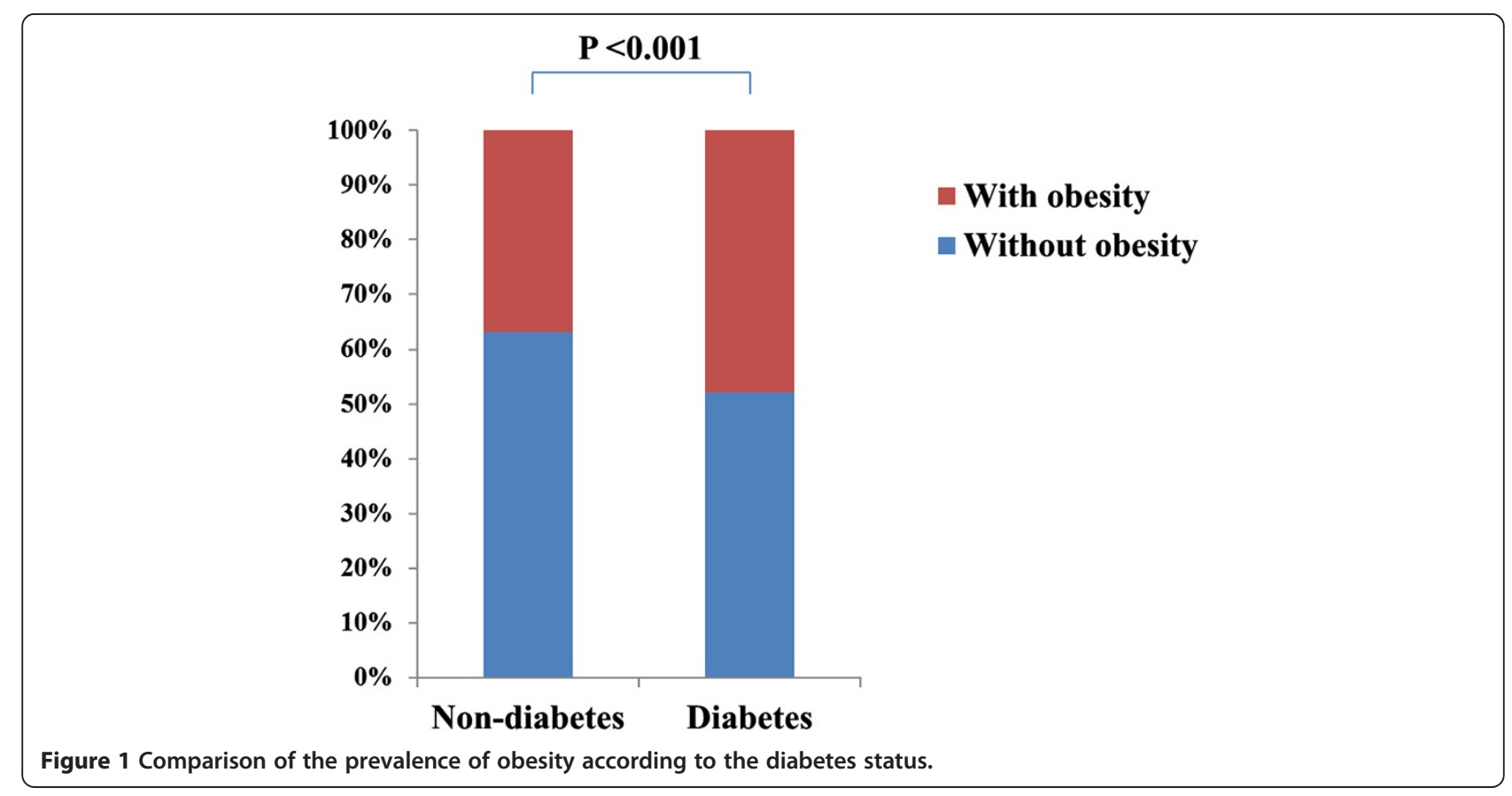




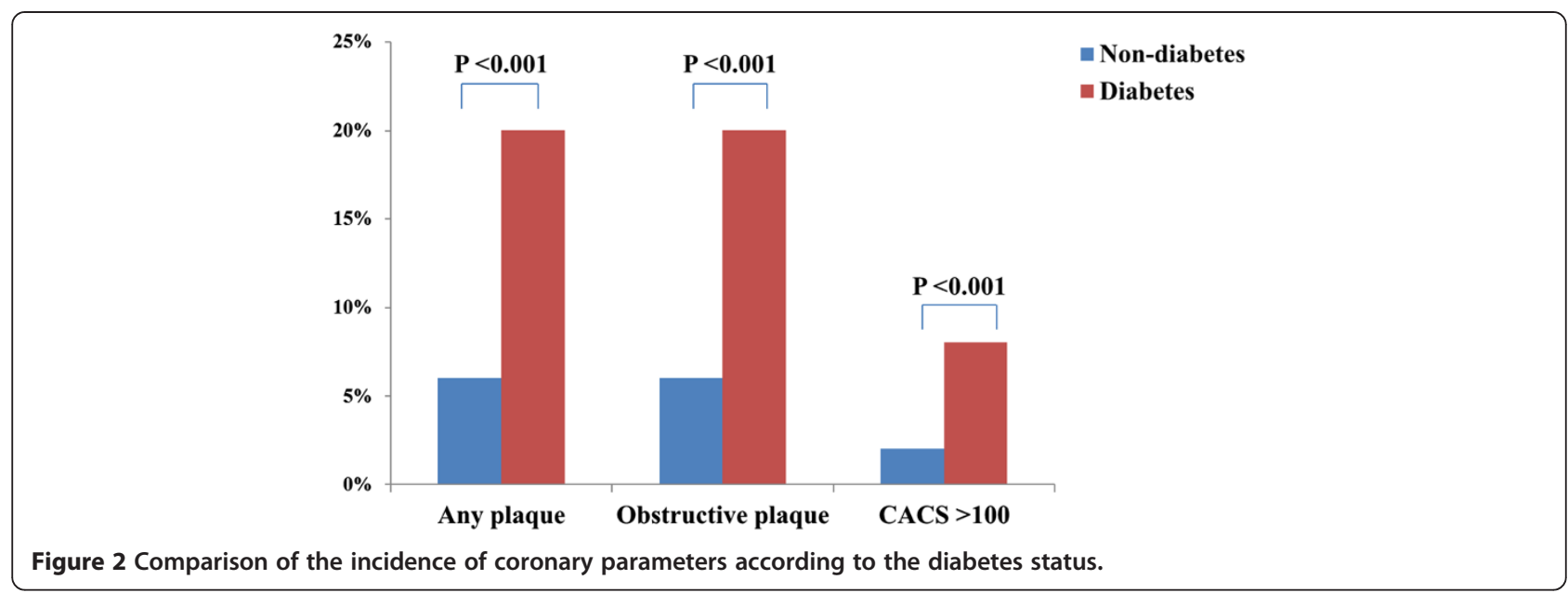

The incidence of any plaque ( $33 \%$ vs. $26 \%, \mathrm{p}<0.001)$, obstructive plaque ( $7 \%$ vs. $6 \%, \mathrm{p}=0.014)$, and CACS $>100$ ( $8 \%$ vs. $6 \%, p=0.002)$ was significantly higher in nondiabetic subjects with obesity than those without obesity. However, there were no significant differences in all these parameters according to the obesity in diabetic subjects (Table 2).

Univariate logistic regression analysis revealed that obesity and BMI were significantly associated with increased risks of any plaque (obesity: odd ratio [OR] 1.36, p <0.001; BMI: OR 1.08, p <0.001), obstructive plaque (obesity: OR 1.29, p = 0.014, BMI: OR 1.07, p <0.001), and CACS $>100$ (obesity: OR 1.38, p = 0.002; BMI: OR 1.07, $\mathrm{p}<0.001)$ in non-diabetic subjects. However, neither obesity nor BMI were significantly associated with increased risks of any plaque (obesity: OR 1.14, $\mathrm{p}=0.323$; BMI: OR $0.98, \mathrm{p}=0.249$ ), obstructive plaque (obesity: OR 1.12, $\mathrm{p}=$ 0.496, BMI: OR 0.97, $\mathrm{p}=0.342$ ), and CACS >100 (obesity: OR 0.92, $\mathrm{p}=0.610$; BMI: OR 0.95, $\mathrm{p}=0.083$ ) in diabetic subjects. After adjusting for age, gender, hypertension, dyslipidemia, current smoking, and mild renal dysfunction, both obesity and BMI were significantly associated with increased risks of any plaque (obesity: OR 1.14, $\mathrm{p}=$ 0.039; BMI: OR 1.04, $\mathrm{p}=0.003$ ) and CACS $>100$ (obesity: OR 1.31, $\mathrm{p}=0.019$; BMI: OR 1.06, $\mathrm{p}=0.004$ ), but not significantly associated with obstructive plaque (obesity: OR 1.16, $\mathrm{p}=0.202$; BMI: OR 1.04, $\mathrm{p}=0.096$ ) in nondiabetic subjects. However, neither obesity nor BMI were significantly associated with increased risks of any plaque (obesity: OR 1.26, p= 0.131; BMI: OR 1.00, $\mathrm{p}=0.903$ ), obstructive plaque (obesity: OR 1.19, $\mathrm{p}=0.332$; BMI: OR $0.99, \mathrm{p}=0.775$ ), and CACS $>100$ (obesity: OR 1.08, $\mathrm{p}=$ 0.685; BMI: OR 0.99, $\mathrm{p}=0.685$ ) in diabetic subjects (Table 3 and Figure 3).

Multivariate logistic models for identifying the impact of diabetes on the presence of any plaque, obstructive plaque, and CACS $<100$ were analyzed after consecutively adjusting for age, gender, hypertension, BMI, dyslipidemia, current smoking, and mild renal dysfunction. All models illustrated that diabetes had a strong impact on the presence of any plaque, obstructive plaque, and CACS $>100$ (Table 4).

\section{Discussion}

To the best of our knowledge, the present study is the first to provide information on the differential association between obesity and coronary atherosclerosis according to the presence of diabetes in the Asian population. Diabetes was strongly associated with all coronary parameters including any plaque, obstructive plaque, and CACS $>100$.

Table 2 Comparison of coronary atherosclerosis according to the obesity status in non-diabetic and diabetic subjects

\begin{tabular}{|c|c|c|c|c|c|c|}
\hline & \multicolumn{2}{|c|}{ Non-diabetes $(n=6,345)$} & \multirow[t]{2}{*}{$P$} & \multicolumn{2}{|c|}{ Diabetes $(n=889)$} & \multirow[t]{2}{*}{$P$} \\
\hline & Non-obesity $(n=4,019)$ & Obesity $(n=2,326)$ & & Non-obesity $(n=465)$ & Obesity $(n=424)$ & \\
\hline Any plaque, $\mathrm{n}(\%)$ & $1055(26)$ & 759 (33) & $<0.001$ & $260(56)$ & $251(59)$ & 0.323 \\
\hline CMP & $785(19)$ & $586(26)$ & $<0.001$ & $226(49)$ & $209(50)$ & 0.837 \\
\hline NCP & $270(7)$ & $173(7)$ & 0.278 & $34(7)$ & $42(9)$ & 0.167 \\
\hline Obstructive plaque, n (\%) & $231(6)$ & $170(7)$ & 0.014 & $87(19)$ & $87(21)$ & 0.496 \\
\hline Obstructive CMP & $190(5)$ & $143(6)$ & 0.015 & $77(17)$ & $71(17)$ & 0.940 \\
\hline Obstructive NCP & $41(1)$ & $27(1)$ & 0.601 & $10(2)$ & $16(4)$ & 0.151 \\
\hline CACS $>100, n(\%)$ & $226(6)$ & $177(8)$ & 0.002 & $95(21)$ & $81(19)$ & 0.610 \\
\hline
\end{tabular}

Data are expressed as $\mathrm{n}(\%)$. CACS, coronary artery calcium score; CMP, calcified or mixed plaque; NCP, non-calcified plaque. 
Table 3 Impact of obesity and BMI on coronary atherosclerosis according to the diabetes status

\begin{tabular}{|c|c|c|c|c|c|c|c|c|c|c|c|c|}
\hline & \multicolumn{4}{|c|}{ Any plaque } & \multicolumn{4}{|c|}{ Obstructive plaque } & \multicolumn{4}{|c|}{ CACS $>100$} \\
\hline & \multicolumn{2}{|c|}{ Univariate } & \multicolumn{2}{|c|}{ Multivariate } & \multicolumn{2}{|c|}{ Univariate } & \multicolumn{2}{|c|}{ Multivariate } & \multicolumn{2}{|c|}{ Univariate } & \multicolumn{2}{|c|}{ Multivariate } \\
\hline & OR & $95 \% \mathrm{Cl}$ & OR & $95 \% \mathrm{Cl}$ & OR & $95 \% \mathrm{Cl}$ & OR & $95 \% \mathrm{Cl}$ & OR & $95 \% \mathrm{Cl}$ & OR & $95 \% \mathrm{Cl}$ \\
\hline \multicolumn{13}{|c|}{ Non-diabetes } \\
\hline Obesity & 1.36 & $1.22-1.52^{*}$ & 1.14 & $1.01-1.30^{\ddagger}$ & 1.29 & $1.05-1.59^{\dagger}$ & 1.16 & $0.93-1.44$ & 1.38 & $1.13-1.69^{\dagger}$ & 1.31 & $1.05-1.65^{\neq}$ \\
\hline BMl & 1.08 & $1.06-1.10^{*}$ & 1.04 & $1.01-1.06^{\dagger}$ & 1.07 & $1.03-1.10^{*}$ & 1.04 & $0.99-1.08$ & 1.07 & $1.04-1.11^{*}$ & 1.06 & $1.02-1.11^{\dagger}$ \\
\hline \multicolumn{13}{|l|}{ Diabetes } \\
\hline Obesity & 1.14 & $0.88-1.49$ & 1.26 & $0.93-1.70$ & 1.12 & $0.81-1.56$ & 1.19 & $0.84-1.70$ & 0.92 & $0.66-1.23$ & 1.08 & $0.75-1.56$ \\
\hline $\mathrm{BMI}$ & 0.98 & $0.93-1.02$ & 1.00 & $0.95-1.05$ & 0.97 & $0.92-1.03$ & 0.99 & $0.93-1.05$ & 0.95 & $0.90-1.01$ & 0.99 & $0.93-1.05$ \\
\hline
\end{tabular}

$\mathrm{BMI}$, body mass index; $\mathrm{CACS}$, coronary artery calcium score; $\mathrm{Cl}$, confidence interval; OR, odds ratio.

Multivariate analyses were adjusted for age, gender, hypertension, dyslipidemia, current smoking, and mild renal dysfunction.

${ }^{*} \mathrm{P}<0.001,{ }^{\dagger} \mathrm{P}<0.005,{ }^{*} \mathrm{P}<0.05$.

Despite a significantly higher prevalence of obesity in diabetic subjects, obesity was independently associated with the presence of CAD and severe coronary calcification only in subjects without established diabetes in a Korean population.

Obesity, a major factor for insulin resistance, is significantly associated with diabetes and CAD [27,28]. However, the criteria and prevalence of obesity is dependent on ethnicity. Despite the increased prevalence of obesity and diabetes in Asia, the clinical features of the development of diabetes in Asia are different from those in other parts of the world [3]. In Korea, previous studies reported that approximately $65 \%$ of subjects with diabetes were non-obese [4], and that impaired insulin secretion was more prominent than insulin resistance in diabetic subjects $[5,6]$. Furthermore, a recent study revealed that diabetes had an incremental impact on subclinical atherosclerosis independent of the metabolic syndrome, for which insulin resistance is a major characteristic, in the Korean population [29]. Accordingly, it is important to identify whether obesity is independently associated with CAD in an Asian population with established diabetes.
CAC is a traditional surrogate marker for coronary atherosclerosis because it is significantly related to the coronary plaque burden $[10,11]$. It may be that the severity of coronary calcification is somewhat different in an Asian population compared to that in a Western population [26]. However, most studies evaluated the association between obesity and CAC in a Western population with conflicting results [13-19]. CCTA has recently been used for evaluating coronary atherosclerosis because of its high diagnostic accuracy in detecting CAD [22,23], and only limited studies investigated the relationship of BMI with coronary atherosclerosis using CCTA. Dores et al. [30] reported that BMI was an independent predictor of CAD, but it was not correlated with the severity of CAD in subjects with suspected CAD. Labounty et al. [31] reported that an increased BMI was associated with a greater prevalence, extent, and severity of CAD and was independently associated with an increased risk of myocardial infarction. However, most participants in these studies were from Western populations, and these studies did not evaluate the differential association of BMI with coronary atherosclerosis according to the presence of diabetes. Furthermore, it has
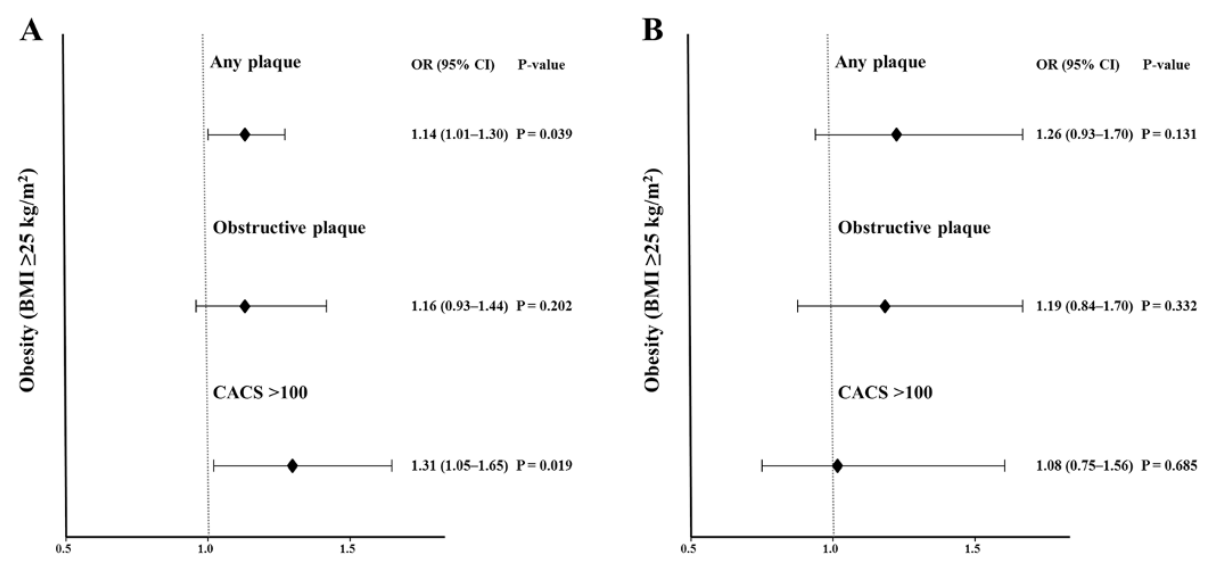

Figure 3 Association between obesity and coronary parameters. (A) Non-diabetes, (B) diabetes. 
Table 4 Multiple logistic regression models for identifying the impact of diabetes on coronary atherosclerosis

\begin{tabular}{|c|c|c|c|c|c|c|}
\hline & \multicolumn{2}{|c|}{ Any plaque } & \multicolumn{2}{|c|}{ Obstructive plaque } & \multicolumn{2}{|c|}{ CACS $>100$} \\
\hline & OR & $95 \% \mathrm{Cl}$ & OR & $95 \% \mathrm{Cl}$ & OR & $95 \% \mathrm{Cl}$ \\
\hline Model 1 & 3.38 & $2.93-3.90^{*}$ & 3.61 & $2.97-4.39^{*}$ & 3.65 & $3.01-4.43^{*}$ \\
\hline Model 2 & 2.37 & $2.03-2.77^{*}$ & 2.43 & $1.98-2.98^{*}$ & 2.25 & $1.82-2.77^{*}$ \\
\hline Model 3 & 2.21 & $1.88-2.59^{*}$ & 2.32 & $1.89-2.85^{*}$ & 2.15 & $1.74-2.67^{*}$ \\
\hline Model 4 & 2.10 & $1.79-2.47^{*}$ & 2.21 & $1.80-2.73^{*}$ & 2.08 & $1.68-2.59^{*}$ \\
\hline Model 5 & 2.05 & $1.75-2.41^{*}$ & 2.17 & $1.67-2.76^{*}$ & 2.04 & $1.64-2.53^{*}$ \\
\hline Model 6 & 2.00 & $1.70-2.35^{*}$ & 2.12 & $1.71-2.61^{*}$ & 2.06 & $1.66-2.56^{*}$ \\
\hline Model 7 & 2.01 & $1.71-2.36^{*}$ & 2.14 & $1.73-2.64^{*}$ & 2.08 & $1.67-2.58^{*}$ \\
\hline Model 8 & 1.96 & $1.67-2.31^{*}$ & 2.07 & $1.67-2.56^{*}$ & 2.05 & $1.65-2.55^{*}$ \\
\hline
\end{tabular}

$\mathrm{BMI}$, body mass index; CACS, coronary artery calcium score; $\mathrm{Cl}$, confidence interval; OR, odds ratio. ${ }^{*} \mathrm{P}<0.001$.

Model 1: Unadjusted.

Model 2: Adjusted for age.

Model 3: Adjusted for age and gender.

Model 4: Adjusted for age, gender, and hypertension.

Model 5: Adjusted for age, gender, hypertension, and BMI.

Model 6: Adjusted for age, gender, hypertension, BMI, and dyslipidemia.

Model 7: Adjusted for age, gender, hypertension, BMI, dyslipidemia, and current smoking.

Model 8: Adjusted for age, gender, hypertension, BMI, dyslipidemia, current smoking, and mild renal dysfunction.

not been investigated whether obesity, defined as a BMI $\geq 25 \mathrm{~kg} / \mathrm{m}^{2}$, is an independent predictor of CAD in Asian patients with diabetes. We evaluated the association between obesity and coronary atherosclerosis using the parameters of any plaque, obstructive plaque, and CACS $>100$ according to the presence of diabetes. The prevalence of obesity was significantly higher in diabetic subjects than in non-diabetic subjects, but the majority of diabetic subjects were non-obese in our Korean population. We identified that diabetes was strongly associated with all coronary atherosclerotic parameters. Despite a significantly higher prevalence of obesity in diabetic subjects than in non-diabetic subjects, obesity was independently associated with the presence of CAD and severe coronary calcification in non-diabetic subjects. These results suggest that obesity is not a useful predictor for CAD in subjects with established diabetes, although it was significantly associated with the development of diabetes in a Korean population. These results might imply that the identification of newly developing diabetes might be important in non-diabetic subjects with obesity; however, considering the incremental impact of diabetes on coronary atherosclerosis, rigorous risk stratification for CAD is necessary in subjects with established diabetes irrespective of the obesity status in the Korean population.

Although obesity is associated with an increased risk of cardiovascular disease [32,33], several studies have suggested an interesting phenomenon, the obesity paradox, which is the protective effect of obesity against adverse clinical outcomes in patients with obstructive CAD [34-36]. However, these studies evaluated the impact of obesity on prognosis only in patients with established CAD. In the present study, diabetes was independently associated with the presence and severity of CAD, but obesity was not independently associated with CAD in subjects with established diabetes. Although the relationship between obesity and prognosis in subjects with diabetes remains uncertain in the Asian population, it may be more important to predict the development of CAD in non-obese subjects with diabetes compared with their obese counterparts considering the protective effect of obesity in subjects with obstructive CAD. Further prospective studies with larger sample sizes are necessary to address this issue.

\section{Limitations}

Several limitations should be acknowledged in the present study. First, we could not eliminate the possible effects of underlying medication for hypertension, dyslipidemia, and diabetes on coronary atherosclerosis because of the observational design of this study. Second, we used only the criterion of BMI $\geq 25 \mathrm{~kg} / \mathrm{m}^{2}$ for defining the obesity status. Although it is well-known that BMI is significantly associated with abdominal fat and waist circumference in the Korean population [37], further evaluation of the association between other anthropometric indices and coronary atherosclerosis according to the presence of diabetes may be necessary in Asian populations.

Despite these limitations, it is novel in that only participants of Asian ethnicity were evaluated in the present study compared with other studies performed in Western populations. In addition, the clinical usefulness of obesity for predicting CAD according to the diabetes status was first evaluated in approximately 7,300 Asian subjects with near-normal kidney function using large-scale CT data. The findings of this study may be helpful to identify the differential association between obesity and CAD according to the diabetes status in the Asian population.

\section{Conclusions}

Despite a significantly higher prevalence of obesity in diabetic subjects than in non-diabetic subjects, the majority of the diabetic subjects were non-obese in our Korean population. Obesity has an independent predictive value for the presence of CAD and severe coronary calcification only in subjects without established diabetes. Considering the incremental impact of diabetes, rigorous risk stratification for CAD might be necessary in diabetic subjects irrespective of the obesity status among Asian population.

\section{Abbreviations}

BMI: Body mass index; CACS: Coronary artery calcium score; CAD: Coronary artery disease; CCTA: Coronary computed tomographic angiography; CAD: Coronary artery disease; Cl: Confidence intervals; CMP: Calcified or mixed plaque; GFR: Glomerular filtration rate; HDL: High-density lipoprotein; LDL: Low-density lipoprotein; MDCT: Multidetector computed tomography; NCP: Non-calcified plaque; OR: Odds ratios. 


\section{Competing interests}

The authors declare that they have no competing interests.

\section{Authors' contributions}

All authors have made substantial contributions. KW and $\mathrm{HC}$ designed the study. IC, CS, and GH conducted all clinical measurements. YK and BC conducted all image measurements. KW and JS conducted the statistical analyses. NC reviewed, corrected and helped finalize the manuscript. All authors read and approved the final manuscript.

\section{Acknowledgment}

This research was supported by the Leading Foreign Research Institute Recruitment Program through the National Research Foundation of Korea, funded by the Ministry of Education, Science, and Technology (2012027176).

\section{Author details}

${ }^{1}$ Division of Cardiology, Yonsei Cardiovascular Center, Yonsei University College of Medicine, 50 Yonsei-ro, Seodaemun-gu, Seoul 120-752, Republic of Korea. ${ }^{2}$ Division of Cardiology, St. Luke's International Hospital, Tokyo, Japan. ${ }^{3}$ Graduate School of Health and Welfare CHA University, Seongnam, Republic of Korea. ${ }^{4}$ Division of Radiology, Yonsei Cardiovascular Center, Yonsei University College of Medicine, Seoul, Republic of Korea. ${ }^{5}$ Severance Biomedical Science Institute, Seoul, Republic of Korea.

\section{Received: 24 April 2014 Accepted: 30 November 2014}

Published: 5 December 2014

\section{References}

1. Welsh M, Mares J, Oberg C, Karlsson T: Genetic factors of importance for beta-cell proliferation. Diabetes Metab Rev 1993, 9:25-36.

2. DeFronzo RA: Pathogenesis of type 2 diabetes mellitus. Med clin North Am 2004, 88:787-835.

3. Yoon KH, Lee JH, Kim JW, Cho JH, Choi YH, Ko SH, Zimmet P, Son HY: Epidemic obesity and type 2 diabetes in Asia. Lancet 2006, 368:1681-1688.

4. Park JY, Lee KU, Kim CH, Kim HK, Hong SK, Park KS, Lee HK, Min HK: Past and current obesity in Koreans with non-insulin-dependent diabetes mellitus. Diabetes Res Clin Pract 1997, 35:49-56.

5. Shin CS, Lee HK, Koh CS, Kim Yl, Shin YS, Yoo KY, Paik HY, Park YS, Yang BG: Risk factors for the development of NIDDM in Yonchon County, Korea. Diabetes Care 1997, 20:1842-1846.

6. Kim DJ, Lee MS, Kim KW, Lee MK: Insulin secretory dysfunction and insulin resistance in the pathogenesis of korean type 2 diabetes mellitus. Metabolism 2001, 50:590-593

7. Agatston AS, Janowitz WR, Hildner FJ, Zusmer NR, Viamonte M Jr, Detrano R: Quantification of coronary artery calcium using ultrafast computed tomography. J Am Coll Cardiol 1990, 15:827-832.

8. Budoff MJ, Shaw LJ, Liu ST, Weinstein SR, Mosler TP, Tseng PH, Flores FR, Callister TQ, Raggi P, Berman DS: Long-term prognosis associated with coronary calcification: observations from a registry of 25,253 patients. J Am Coll Cardiol 2007, 49:1860-1870.

9. Detrano R, Guerci AD, Carr JJ, Bild DE, Burke G, Folsom AR, Liu K, Shea S, Szklo M, Bluemke DA, O'Leary DH, Tracy R, Watson K, Wong ND, Kronmal RA: Coronary calcium as a predictor of coronary events in four racial or ethnic groups. N Engl J Med 2008, 358:1336-1345.

10. Rumberger JA, Simons DB, Fitzpatrick LA, Sheedy PF, Schwartz RS: Coronary artery calcium area by electron-beam computed tomography and coronary atherosclerotic plaque area. A histopathologic correlative study. Circulation 1995, 92:2157-2162.

11. Bonow RO: Clinical practice. Should coronary calcium screening be used in cardiovascular prevention strategies? N Engl J Med 2009, 361:990-997.

12. Greenland P, Bonow RO, Brundage BH, Budoff MJ, Eisenberg MJ, Grundy SM, Lauer MS, Post WS, Raggi P, Redberg RF, Rodgers GP, Shaw LJ, Taylor AJ, Weintraub WS, Harrington RA, Abrams J, Anderson JL, Bates ER, Grines CL, Hlatky MA, Lichtenberg RC, Lindner JR, Pohost GM, Schofield RS, Shubrooks SJ Jr, Stein JH, Tracy CM, Vogel RA, Wesley DJ: ACCF/AHA 2007 clinical expert consensus document on coronary artery calcium scoring by computed tomography in global cardiovascular risk assessment and in evaluation of patients with chest pain. Circulation 2007, 115:402-426.

13. Oei HH, Vliegenthart R, Hofman A, Oudkerk M, Witteman JC: Risk factors for coronary calcification in older subjects. The Rotterdam coronary calcification study. Eur Heart J 2004, 25:48-55.
14. Bild DE, Folsom AR, Lowe LP, Sidney S, Kiefe C, Westfall AO, Zheng ZJ, Rumberger J: Prevalence and correlates of coronary calcification in black and white young adults: the coronary artery risk development in young adults (CARDIA) study. Arterioscler Thromb Vasc Biol 2001, 21:852-857.

15. Park HE, Kim MK, Choi SY, Lee W, Shin CS, Cho SH, Oh BH: The prevalence and distribution of coronary artery calcium in asymptomatic Korean population. Int J Cardiovasc Imaging 2012, 28:1227-1235.

16. Dakik HA, Skouri HN, Mehio-Sibai A, Sibai T, Alam S, Sawaya J, Nasrallah A, Wehbeh C, Ayach K, Abchee AB: Prevalence of coronary artery calcium among asymptomatic men and women in a developing country: comparison with the USA data. Atherosclerosis 2005, 183:141-145.

17. Schmermund A, Lehmann N, Bielak LF, Yu P, Sheedy PF II, Cassidy-Bushrow AE, Turner ST, Moebus S, Möhlenkamp S, Stang A, Mann K, Jöckel KH, Erbel R, Peyser PA: Comparison of subclinical coronary atherosclerosis and risk factors in unselected populations in Germany and US-America. Atherosclerosis 2007, 195:e207-e216.

18. Taylor AJ, Feuerstein I, Wong H, Barko W, Brazaitis M, O'Malley PG: Do conventional risk factors predict subclinical coronary artery disease? Results from the prospective army coronary calcium project. Am Heart $J$ 2001, 141:463-468.

19. Kovacic JC, Lee P, Baber U, Karajgikar R, Evrard SM, Moreno P, Mehran R, Fuster V, Dangas G, Sharma SK, Kini AS: Inverse relationship between body mass index and coronary artery calcification in patients with clinically significant coronary lesions. Atherosclerosis 2012, 221:176-182.

20. Budoff MJ, Dowe D, Jollis JG, Gitter M, Sutherland J, Halamert E, Scherer M, Bellinger R, Martin A, Benton R, Delago A, Min JK: Diagnostic performance of 64-multidetector row coronary computed tomographic angiography for evaluation of coronary artery stenosis in individuals without known coronary artery disease: results from the prospective multicenter ACCURACY (Assessment by Coronary Computed Tomographic Angiography of Individuals Undergoing Invasive Coronary Angiography) trial. J Am Coll Cardiol 2008, 52:1724-1732.

21. Miller JM, Rochitte CE, Dewey M, Arbab-Zadeh A, Niinuma H, Gottlieb I, Paul N, Clouse ME, Shapiro EP, Hoe J, Lardo AC, Bush DE, de Roos A, Cox C, Brinker J, Lima JA: Diagnostic performance of coronary angiography by 64-row $C T$. N Engl J Med 2008, 359:2324-2336.

22. Hoffmann MH, Shi H, Schmitz BL, Schmid FT, Lieberknecht M, Schulze R, Ludwig B, Kroschel U, Jahnke N, Haerer W, Brambs HJ, Aschoff AJ: Noninvasive coronary angiography with multislice computed tomography. J Am Med Assoc 2005, 293:2471-2478.

23. Cho I, Min HS, Chun EJ, Park SK, Choi Y, Blumenthal RS, Rivera JJ, Nasir K, Kim YJ, Sohn DW, Oh BH, Park YB, Chang HJ: Coronary atherosclerosis detected by coronary $\mathrm{CT}$ angiography in asymptomatic subjects with early chronic kidney disease. Atherosclerosis 2010, 208:406-411.

24. Hendel RC, Patel MR, Kramer CM, Poon M, Carr JC, Gerstad NA, Gillam LD, Hodgson JM, Kim RJ, Lesser JR, Martin ET, Messer JV, Redberg RF, Rubin GD, Rumsfeld JS, Taylor AJ, Weigold WG, Woodard PK, Brindis RG, Douglas PS, Peterson ED, Wolk MJ, Allen JM: ACCF/ACR/SCCT/SCMR/ASNC/NASCI/SCAI/ SIR 2006 appropriateness criteria for cardiac computed tomography and cardiac magnetic resonance imaging: a report of the American College of Cardiology Foundation Quality Strategic Directions Committee Appropriateness Criteria Working Group, American College of Radiology, Society of Cardiovascular Computed Tomography, Society for Cardiovascular Magnetic Resonance, American Society of Nuclear Cardiology, North American Society for Cardiac Imaging, Society for Cardiovascular Angiography and Interventions, and Society Of Interventional Radiology. J Am Coll Cardiol 2006, 48:1475-1497.

25. Mark DB, Berman DS, Budoff MJ, Carr JJ, Gerber TC, Hecht HS, Hlatky MA Hodgson JM, Lauer MS, Miller JM, Morin RL, Mukherjee D, Poon M, Rubin GD, Schwartz RS: ACCF/ACR/AHA/NASCI/SAIP/SCAI/SCCT 2010 expert consensus document on coronary computed tomographic angiography: a report of the American college of cardiology foundation task force on expert consensus documents. Circulation 2010, 121:2509-2543.

26. Nasir K, Shaw LJ, Liu ST, Weinstein SR, Mosler TR, Flores PR, Flores FR, Raggi P, Berman DS, Blumenthal RS, Budoff MJ: Ethnic differences in the prognostic value of coronary artery calcification for all-cause mortality. J Am Coll Cardiol 2007, 50:953-960.

27. Chan JM, Rimm EB, Colditz GA, Stampfer MJ, Willett WC: Obesity, fat distribution, and weight gain as risk factors for clinical diabetes in men. Diabetes Care 1994, 17:961-969. 
28. McGill HC Jr, McMahan CA, Herderick EE, Zieske AW, Malcom GT, Tracy RE, Strong JP: Obesity accelerates the progression of coronary atherosclerosis in young men. Circulation 2002, 105:2712-2718.

29. Won KB, Chang HJ, Kim HC, Jeon K, Lee H, Shin S, Cho IJ, Park SH, Lee SH, Jang Y: Differential impact of metabolic syndrome on subclinical atherosclerosis according to the presence of diabetes. Cardiovasc Diabeto 2013, 12:41.

30. Dores H, de Araújo Gonçalves P, Carvalho MS, Sousa PJ, Ferreira A, Cardim N, Carmo MM, Aleixo A, Mendes M, Machado FP, Roquette J, Marques H: Body mass index as a predictor of the presence but not the severity of coronary artery disease evaluated by cardiac computed tomography. Eur $J$ Prev Cardiol 2014, 21:1387-1393.

31. Labounty TM, Gomez MJ, Achenbach S, Al-Mallah M, Berman DS, Budoff MJ, Cademartiri F, Callister TQ, Chang HJ, Cheng V, Chinnaiyan KM, Chow B, Cury R, Delago A, Dunning A, Feuchtner G, Hadamitzky M, Hausleiter J, Kaufmann P, Kim YJ, Leipsic J, Lin FY, Maffei E, Raff G, Shaw LJ, Villines TC, Min JK: Body mass index and the prevalence, severity, and risk of coronary artery disease: an international multicentre study of 13,874 patients. Eur Heart J Cardiovasc Imaging 2013, 14:456-463.

32. Calle EE, Thun MJ, Petrelli JM, Rodriguez C, Heath CW Jr: Body mass index and mortality in a prospective cohort of US adults. N Engl J Med 1999, 341:1097-1105.

33. Peeters A, Barendregt JJ, Wilekens F, Mackenbach JP, Al Mamun A, Bonneux L: Obesity in adulthood and its consequences for life expectancy: a life-table analysis. Ann Intern Med 2003, 138:24-32.

34. Hastie CE, Padmanabhan S, Slack R, Pell AC, Oldroyd KG, Flapan AD, Jennings KP, Irving J, Eteiba H, Dominiczak AF, Pell JP: Obesity paradox in a cohort of 4880 consecutive patients undergoing percutaneous coronary intervention. Eur Heart J 2010, 31:222-226.

35. Bucholz EM, Rathore SS, Reid KJ, Jones PG, Chan PS, Rich MW, Spertus JA, Krumholz HM: Body mass index and mortality in acute myocardial infarction patients. Am J Med 2012, 125:796-803.

36. Won KB, Kim BK, Chang HJ, Shin DH, Kim JS, Ko YG, Choi D, Ha JW, Hong $M K$, Jang $Y$ : Metabolic syndrome does not impact long-term survival in patients with acute myocardial infarction after successful percutaneous coronary intervention with drug-eluting stents. Catheter Cardiovasc Interv 2014, 83:713-720.

37. Hwang MJ, Chung WS, Gallagher D, Kim DY, Shin HD, Song MY: How useful is waist circumference for assessment of abdominal obesity in Korean pre-menopausal women during weight loss? Asia Pac J Clin Nutr 2008, 17:229-234.

\section{doi:10.1186/1758-5996-6-134}

Cite this article as: Won et al:: Differential association between obesity and coronary artery disease according to the presence of diabetes in a Korean population. Diabetology \& Metabolic Syndrome 2014 6:134.

\section{Submit your next manuscript to BioMed Central and take full advantage of:}

- Convenient online submission

- Thorough peer review

- No space constraints or color figure charges

- Immediate publication on acceptance

- Inclusion in PubMed, CAS, Scopus and Google Scholar

- Research which is freely available for redistribution 